\title{
Characterization and optimization of colon targeted S-adenosyl-L-methionine loaded chitosan nanoparticles
}

\author{
Ahmet Doğan ERGİN ${ }^{1}$ * D , Zerrin SEZGİN BAYINDIR ${ }^{1}$ iD, Nilüfer YÜKSEL ${ }^{1}$ \\ 1 Department of Pharmaceutical Technology, Faculty of Pharmacy, Ankara University, Ankara, Turkey. \\ * Corresponding Author. E-mail: adergin@ankara.edu.tr (A.D.E.); Tel. +90-312-230 3155.
}

Received: 01 August 2019 / Revised: 23 August 2019/ Accepted: 29 August 2019

\begin{abstract}
S-adenosyl-L-methionine (SAMe) is an endogenic methyl donor naturally present in all living cells; it has high water solubility, but its bioavailability is low in oral administration due to the first pass effect in the liver. The aim of this study is to prepare colon targeted chitosan nanoparticles containing SAMe by ionic gelation. In the preparation of the formulations, the effects of chitosan concentration, tripolyphosphate (TPP) concentration and the amount of SAMe on the specifications of the nanoparticles such as particle size, zeta potential, encapsulation efficiency, and process yield, were investigated. Drug-excipient interactions were evaluated by differential scanning calorimetry (DSC) and Fourier transform infrared (FTIR) spectroscopy. The obtained nanoparticles showed bimodal particle size distribution ranging between 228.3-763.9 $\mathrm{nm}$ and their zeta potentials were within 14.10-23.30 $\mathrm{mV}$. The drug encapsulation efficiencies and process yields of the nanoparticles were low. However, when the effects of the process parameters on the characteristics of nanoparticles were examined, the chitosan concentration and SAMe amount were significant parameters affecting particle size. The chitosan concentration was also found to have a significant effect on process yield $(\mathrm{p}<0.05)$. Drug release from nanoparticles was evaluated according to different kinetic models and it was found that the release mechanism was Fickian diffusion.
\end{abstract}

KEYWORDS: S-adenosylmethionine; chitosan; nanoparticle; colon; bioavailibility.

\section{INTRODUCTION}

The efficacy of a drug is measured by the amount, rate and residence time at which the drug is made available at the site of action from the dosage form. This efficacy is also directly related to the route of administration of the dosage form. Oral administration is the most preferred route in administration of drugs because of its cost-effectiveness, non-invasiveness, ease of storage, patient compliance and lack of sterility problems. Today, $73 \%$ of the drugs are given by the oral route $[1,2]$.

Micro- and nanoparticles are important alternative systems for oral delivery of drugs and proteins. Initially, Birrenbach and Speiser (1976) described the nanoparticles, then, it was shown that nanoparticles with appropriate size and surface characteristics can protect drugs from enzymatic degradation, improve absorption and effectiveness, while decreasing toxicity by improving the pharmacokinetic properties of drugs [1-4]. Therefore encapsulated drugs in the nanoparticles became more stable in the gastrointestinal tract.

Nanoparticles have some advantages over conventional dosage forms such as tablets, capsules. Small particles are particularly important for targeting to the colon due to easier penetration into mucus layer and their relatively lower mass. Nanoparticles accumulate cumulatively in the diseased or inflamed colon and a higher therapeutic effect is achieved [5].

Chitosan consisting of $1 \rightarrow 4$ linked 2-amino-2-deoxy-glucopyranose (GlcN) and 2-acetamido-2-deoxyd-glucopyranose (GlcNAc) residues, is a linear polycationic polymer obtained by alkaline Ndeacetylation. Due to its interesting properties such as biocompatibility, biodegredability, bioavailability enhancement and mucoadhesion, it is used in the preparation of various oral drug delivery systems. Chitosan increases bioavailability of drugs by interacting with the cell membranes and opening epithelial tight junctions due to its cationic structure [6-8]. Chitosan nanoparticles have been used frequently in recent years to carry drugs to the colon $[9,10]$.

How to cite this article: Ergin AD, Sezgin-Bayındir, Z, Yüksel, N. Characterization and optimization of colon targeted S-adenosyl-L-methionine loaded chitosan nanoparticles. J Res Pharm. 2019; 23(5): 914-926. 
Chitosan forms complexes with metal anions or small, multi- charged anions such as sulfate, citrate and phosphate by ionic interaction of the amine groups on its structure. The ionic gelation method is advantageous in many aspects. This method is relatively simple and easy to use for encapsulation of sensitive molecules such as peptides and proteins due to the absence of organic solvent and high temperature $[6,11,12]$.

S-Adenosyl-L-methionine (SAMe) is found in all living cell and vital metabolite for methylation, aminopropylation and transsulphuration pathways. After determination of its chemical structure in 1952, many researches are performed on SAMe (Figure 1). Clinical trials of SAMe have been conducted in many diseases such as depression, dementia, liver diseases, vacuolar myelopathy and osteoarthritis following elucidation of its biochemical and molecular role in cell metabolism and positive results have been obtained $[13,14]$. The recommended dose in clinical trials on psychiatric disorders is $800-1600 \mathrm{mg}$ a day. However, due to its degradation in gastrointestinal tract, first-pass effect in liver and low permeability, only $1 \%$ of the administered dose can reach the systemic circulation. Although SAMe is an important alternative in the treatment of many diseases mentioned above, there are only a few studies on improving its bioavailability [13$16]$.

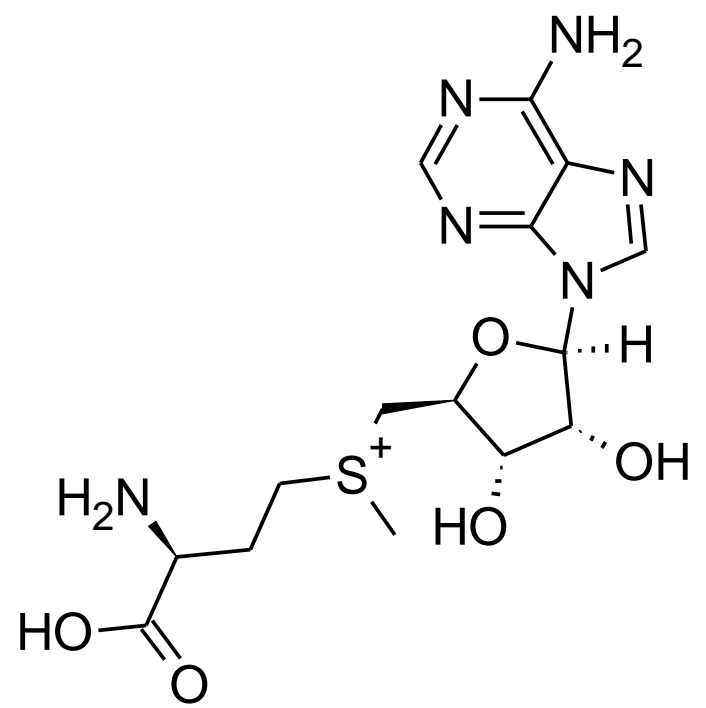

Figure 1. Chemical structure of S-Adenosyl-L-methionine.

In this study, it was intended to increase the bioavailability of oral SAMe by providing its absorption from colon so that the first pass effect will be substantially eliminated. To achieve this goal effectively, it was planned (i) to prepare nanoparticle formulations with chitosan, (ii) to study the effect of formulation variables on the properties of nanoparticles, (iii) to optimize the formulations by a factorial design, and (iv) to characterize the nanoparticles physicochemically.

\section{RESULTS AND DISCUSSION}

\subsection{Development of a spectrophotometric method for SAMe}

SAMe solutions were prepared in water, simulated gastric fluid ( $\mathrm{pH}$ 1.2) (SGF) and simulated colonic fluid ( $\mathrm{pH}$ 5.8) ( SCoF2) at a concentration of $50 \mu \mathrm{g} / \mathrm{mL}$ and the wavelengths ( $\lambda$ max $)$ of maximum absorbances of these solutions were determined by taking the spectrum between $200-400 \mathrm{~nm}$. According to determination coefficients, there was a linear relationship in all three medium. Regression analyses were performed as described in section 4.3. The regression results of the formulations are given in the Table 1.

As analytical validation parameters, linearity and range, precision (repeatability and intermediate precision), selectivity, limit of detection (LOD), and limit of quantification (LOQ) were examined. Results were given in Table 1. Acceptance criteria for evaluation of these parameters were determined with reference to official guidelines, books and scientific studies [17-19]. Obtained validation values were within the acceptance limits (relative standard deviation below $2 \%$ ). According to the selectivity parameters, SAMe does not interfere with any substance in the formulation (data not shown). 
Table 1. Statistical results of linear regression in different media for SAMe assay.

\begin{tabular}{|c|c|c|c|}
\hline & Water & SGF & SCoF2 \\
\hline$\lambda_{\max }(\mathrm{nm})$ & 260 & 257 & 259 \\
\hline Range & $2.5-50 \mu \mathrm{g} \mathrm{mL}^{-1}$ & 2.5-50 $\mu \mathrm{g} \cdot \mathrm{mL}^{-1}$ & $2.5-50 \mu \mathrm{g} \cdot \mathrm{mL}^{-1}$ \\
\hline Slope & 0.01887 & 0.02008 & 0.01974 \\
\hline \multirow[t]{2}{*}{ Slope range $(95 \% \mathrm{CI})$} & Lower limit:0.0188 & Lower limit:0.0200 & Lower limit:0.01970 \\
\hline & Upper limit:0.0190 & Upper limit:0.0201 & Upper limit:0.01978 \\
\hline Intercept & -0.006690 & -0.004610 & -0.004746 \\
\hline \multirow[t]{2}{*}{ Intercept range $(95 \% \mathrm{CI})$} & Lower limit : -0.0089 & Lower limit :-0.0062 & Lower limit :-0.0057 \\
\hline & Upper limit : -0.0045 & Upper limit :-0.0031 & Upper limit :-0.0038 \\
\hline $\begin{array}{l}\text { Within-day precision } \\
\text { (RSD\%) }\end{array}$ & 0.0342 & 0.0736 & 0.0372 \\
\hline $\begin{array}{l}\text { Between-day precision } \\
\text { (RSD\%) }\end{array}$ & 0.0730 & 0.0181 & 0.0126 \\
\hline Determination coefficient & 0.9997 & 0.9998 & 0.9999 \\
\hline LOD / LOQ (ng.mL $\left.{ }^{-1}\right)$ & $635.5 / 1906$ & $199.7 / 665.8$ & $328.8 / 986.2$ \\
\hline
\end{tabular}

\subsection{Nanoparticle preparation and characterization}

Chitosan nanoparticles were prepared by ionotropic gelation method by adding dropwise TPP solution to chitosan solution. Chitosan chloride (Protasan ${ }^{\circledR} \mathrm{CL} 214$ ) was used due to its solubility in water. Protasan ${ }^{\circledR}$ CL 214 has a viscosity of $20-200$ mPa.s, a molecular weight of $150-400 \mathrm{kDa}$, and its deacetylation degree is $>90 \%$. In the production of chitosan nanoparticles, the $\mathrm{pH}$ of the chitosan solution is very important for ionic gelation. Chitosan has a $\mathrm{pKa}$ of about 6.5 and its charge density varies with the $\mathrm{pH}$ of the medium. Su and $\mathrm{Zhu}$ (2002) examined the effect of ambient $\mathrm{pH}$ on the degree of protonation of chitosan. When they increased the $\mathrm{pH}$ from 4.5 to 8.0, they observed that the degree of protonation was decreased from $100 \%$ to $0 \%$. The highest degree of protonation was observed at $\mathrm{pH} 4.7$ [20]. Fan et al. (2012) examined the effect of chitosan solution $\mathrm{pH}$ on nanoparticle formation. It was observed that there was no monomodal particle size distribution below $\mathrm{pH} 4.5$ and microparticles started to assemble above pH 5.2 [21].

In the present study, the $\mathrm{pH}$ of chitosan solution was adjusted to 4.7. Nanoparticles were formed by interacting cationic chitosan with negatively charged TPP. Before starting to the formulation development, preformulation studies were performed to determine the range of formulation and process parameters and then, F1-F8 formulations were prepared. Characteristics of the nanoparticles prepared from different formulations were given in Table 2.

The particle size distributions of different nanoparticle formulations were bimodal (Figure 2) and the mean particle size was between 228.3- $763.9 \mathrm{~nm}$. However, the PDI values of all chitosan nanoparticles were less than 0.7 indicating the narrow size distributions (Table 2). The results of nonlinear regression analysis (B coefficients, $R^{2}$ and $p$ values) are shown in Table 3 . The B coefficients and $p$ values of the single factors indicate the linear effects of the factors on the model, while the coefficients and $p$ values of the multiple factors $\left(X_{1} X_{2}\right.$, $X_{1} X_{3}, X_{2} X_{3}, X_{1} X_{2} X_{3}$ ) indicate the effect of factors' interactions on the model. The negative signs of the coefficients show the antagonistic effect on the model while the positive sign shows the synergistic effect. Factors contribution to the model are not important if $\mathrm{p}$ is larger than 0.05 and can be considered as a negligible. According to these results, there was a significant correlation in terms of particle size by independent factors $\left(\mathrm{R}^{2}=0.9997\right)$ and chitosan concentration $\left(X_{1}\right)$ and SAMe amount $\left(X_{3}\right)$ had a significant effect on particle size $(\mathrm{p}<0.05)$. In addition, there was a significant effect on particle size of binary and triple interactions of three factors (Table 3). As seen in Figure 3, higher amount of chitosan and SAMe in the formulations led to larger nanoparticles. 


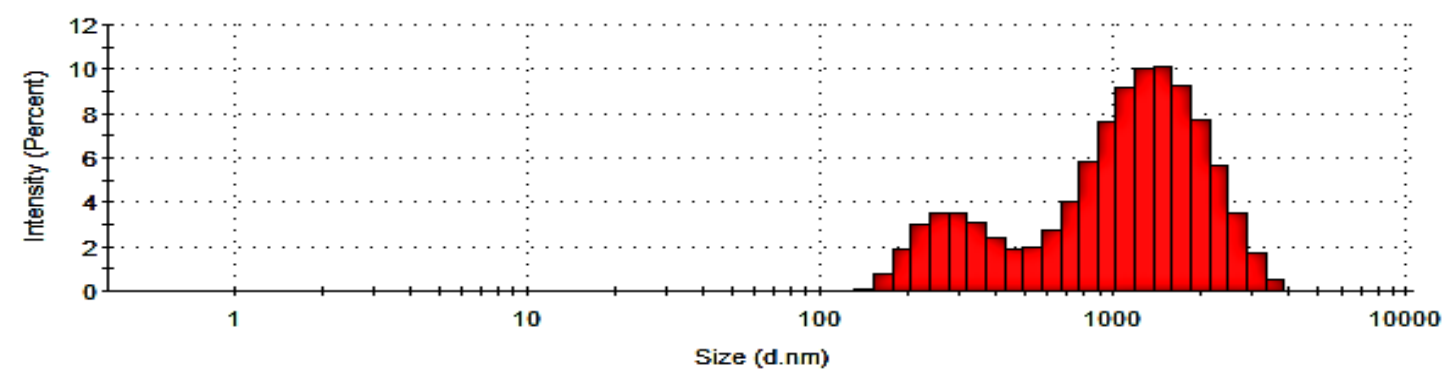

Figure 2. Particle size distribution of F5 formula.

Table 2. Characteristics of chitosan nanoparticles prepared from different formulations.

\begin{tabular}{cccccc}
\hline Formula code & $\begin{array}{c}\text { Size } \pm \text { SE } \\
(\mathbf{n m})\end{array}$ & PDI & $\begin{array}{c}\text { Zeta Potential } \pm \text { SE } \\
(\mathbf{~ m V})\end{array}$ & $\begin{array}{c}\text { Encapsulation Efficiency } \% \\
\pm \text { SE }\end{array}$ & Process Yield\% \\
\hline F1 & $228.3 \pm 5.875$ & $0.439 \pm 0.0245$ & $14.10 \pm 0.727$ & $6.450 \pm 1.400$ & 31.70 \\
\hline F2 & $363.0 \pm 6.280$ & $0.425 \pm 0.018$ & $20.20 \pm 0.941$ & $3.560 \pm 0.280$ & 30.60 \\
\hline F3 & $429.6 \pm 23.05$ & $0.603 \pm 0.048$ & $17.70 \pm 1.599$ & $9.580 \pm 1.995$ & 35.90 \\
\hline F4 & $389.9 \pm 5.626$ & $0.453 \pm 0.056$ & $15.20 \pm 0.416$ & $9.302 \pm 0.840$ & 34.60 \\
\hline F5 & $763.9 \pm 34.94$ & $0.398 \pm 0.046$ & $18.40 \pm 0.924$ & $16.03 \pm 0.780$ & 11.06 \\
\hline F6 & $268.8 \pm 1.292$ & $0.333 \pm 0.023$ & $23.30 \pm 0.716$ & $12.44 \pm 0.370$ & 13.70 \\
\hline F7 & $484.8 \pm 14.29$ & $0.448 \pm 0.003$ & $16.90 \pm 1.905$ & $2.520 \pm 1.199$ & 20.16 \\
\hline F8 & $351.2 \pm 14.87$ & $0.553 \pm 0.014$ & $15.40 \pm 0.831$ & $0.500 \pm 0.302$ & 24.14 \\
\hline
\end{tabular}

Encapsulation efficiency of SAMe in chitosan nanoparticles was quite low (Table 2). All three formulation parameters on encapsulation efficiency were found insignificance $(p>0.05)$ (Table 3$)$. The aqueous solubility of SAMe is very high $\left(1.19 \mathrm{mg} . \mathrm{mL}^{-1}\right)$ and its net charge is positive. Due to its cationic properties, SAMe was not effectively loaded into a cationic drug delivery system such as chitosan. Janes et al. (2001), tried to load anticancer drug, doxorubicin hydrochloride (DOX-HCl) which is cationic and water-soluble, into chitosan nanoparticles. Encapsulation efficiency was very low and a complexation approach was applied in order to increase the low encapsulation efficiency. DOX- $\mathrm{HCl}$ was reacted to an opposite charged polyanion, dextran sulfate and the formed complex was loaded into nanoparticles. This modification doubled encapsulation efficiency of $\mathrm{DOX}-\mathrm{HCl}$ [22]. A similar approach can be used to improve SAMe loading in nanoparticles.

According to the obtained data, process yield was between 11.06 - 35.9\% (Table 2). Nanoparticle formation was associated with ionic gelation of chitosan and TPP in the medium. However, non-gelling part of components and a large quantity of the SAMe was remained in supernatant solution leading to low recovery and encapsulation efficiency. When nonlinear regression results were examined, only the chitosan concentration had a significant effect on the process yield (Table 3$)(p<0.05)$. This result is compatible with the literature data [23]. In Figure 3, decrease of the process yield was observed with increasing chitosan concentration.

Zeta potential is defined as the electrical voltage on the particles. As the zeta potential value increases, the particles repel each other with more force, the tendency of aggregation decreases and the particles form a more stable profile. The zeta potentials of the chitosan nanoparticles were between 14.1-20.7 $\mathrm{mV}$. The zeta potential was positive due to amine groups of chitosan in acidic $\mathrm{pH}$ (Table 2) In the factorial design, the investigated formulation parameters did not affect the zeta potential $(p>0.05)$ (Table 3) [23].

Among the prepared chitosan nanoparticle formulations, the formula F5 had the highest encapsulation efficiency. Subsequent dissolution rate studies, FTIR and DSC analysis were carried out on F5 formula. 

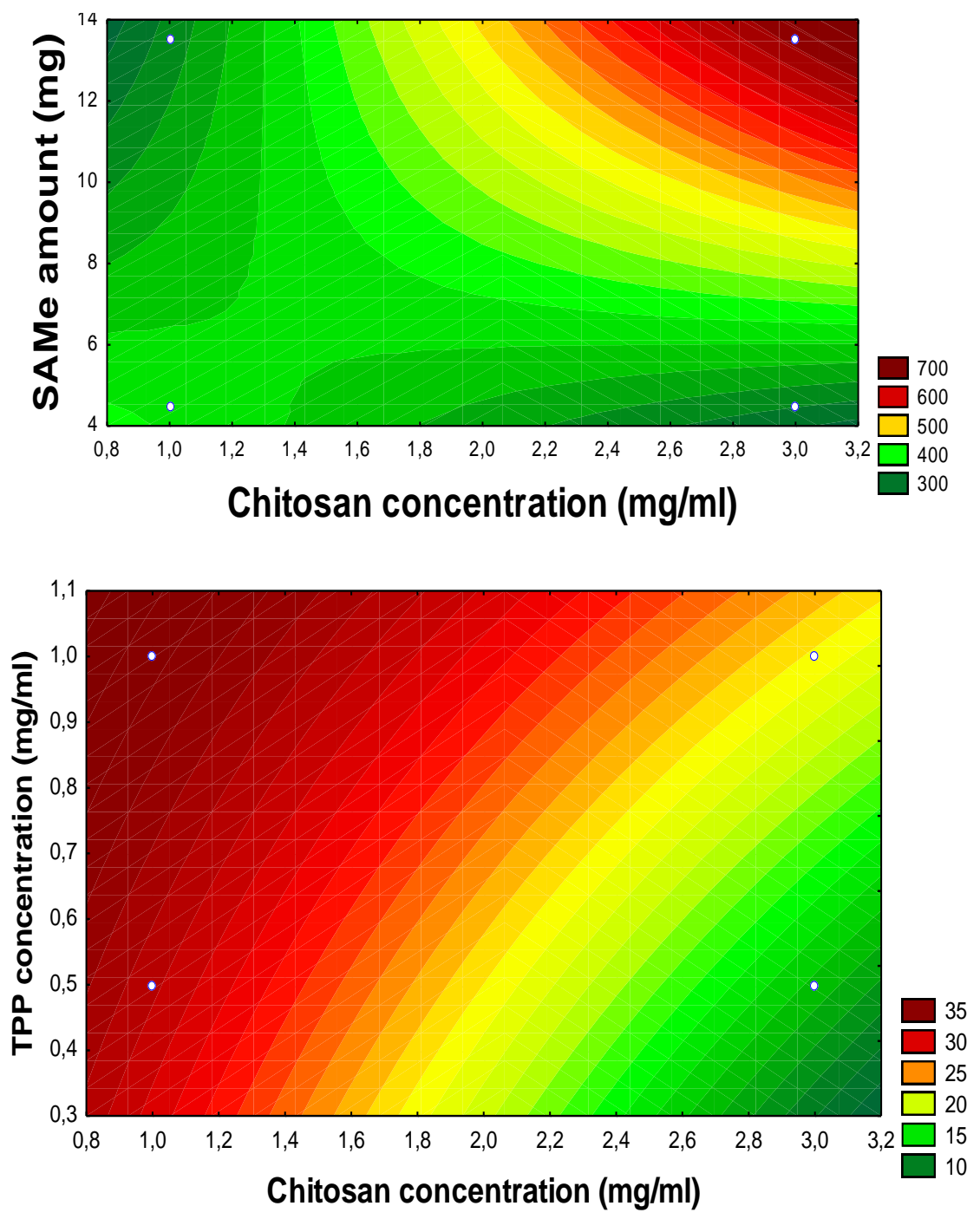

Figure 3. Contour plot graphs for particle size (Y1) and process yield (Y5).

Table 3. Results of regression analysis and P values obtained from analysis.

\begin{tabular}{|c|c|c|c|c|c|c|c|c|c|c|}
\hline \multirow[b]{2}{*}{ Factor } & \multicolumn{2}{|c|}{ Particle size(Y1) } & \multicolumn{2}{|c|}{ PDI(Y2) } & \multicolumn{2}{|c|}{$\begin{array}{c}\text { Zeta Potential } \\
\text { (Y3) }\end{array}$} & \multicolumn{2}{|c|}{$\begin{array}{c}\text { Encapsulation } \\
\text { Efficiency \% (Y4) }\end{array}$} & \multicolumn{2}{|c|}{$\begin{array}{c}\text { Process Yield \% } \\
\text { (Y5) }\end{array}$} \\
\hline & Coefficient & $\mathrm{p}$ & Coefficient & $\mathrm{p}$ & Coefficient & $\mathrm{p}$ & Coefficient & $\mathrm{p}$ & Coefficient & $\mathrm{p}$ \\
\hline$X_{1}$ & 56.192 & $0.0020^{*}$ & -0.0092 & 0.8108 & 0.913 & 0.3764 & 0.066 & 0.9238 & -7.846 & $0.0242^{*}$ \\
\hline$X_{2}$ & 4.983 & 0.1832 & 0.0434 & 0.3259 & -1.413 & 0.2228 & -1.814 & 0.0981 & 3.346 & 0.1147 \\
\hline$X_{3}$ & 65.667 & $0.0014^{*}$ & 0.0298 & 0.4687 & -0.813 & 0.4209 & 0.834 & 0.3053 & -0.06 & 0.7749 \\
\hline$X_{1} X_{2}$ & -52.067 & $0.0023^{*}$ & -0.0045 & 0.9041 & -1.063 & 0.3195 & -4.031 & 0.0224 & 1.296 & 0.4065 \\
\hline$X_{1} X_{3}$ & 89.417 & $0.0008^{*}$ & -0.0112 & 0.7715 & 0.088 & 0.9237 & 0.047 & 0.9461 & -1.006 & 0.5032 \\
\hline$X_{2} X_{3}$ & -22.342 & $0.0122^{*}$ & -0.0185 & 0.6362 & 1.813 & 0.1543 & -0.239 & 0.7088 & -0.2637 & 0.8516 \\
\hline$X_{1} X_{2} X_{3}$ & -65.941 & $0.0014^{*}$ & -0.0525 & 0.2584 & -0.338 & 0.7170 & 0.389 & 0.5917 & -0.3137 & 0.8243 \\
\hline Intercept & 56.192 & $0.0020^{*}$ & 0.4708 & 0.0051 & 17.712 & 0.002 & 7.289 & 0,0070 & 25.354 & 0.0024 \\
\hline$R^{2 * *}$ & 0.9997 & & 0.7236 & & 0.8533 & & 0.9727 & & 0.9706 & \\
\hline
\end{tabular}




\subsection{Drug release studies}

Data obtained from the release test of F5 formulation was compared with the data from pure SAMe. Chitosan nanoparticles delayed the release of the active substance and $51.29 \%$ of SAMe was released from nanoparticles while $70 \%$ of pure SAMe was dissolved at the end of the first hour (Figure 4). Sustained release was achieved over $8 \mathrm{~h}$ and the cumulative SAMe release was $96.8 \%$. After fitting mathematical models to the release data of SAMe loaded nanoparticles (F5 formulation), the selection of the model which fits best to the release data was depended upon the determination coefficient (Rsqr, R 2, or COD), the adjusted coefficient of determination (Rsqr_adj or $\mathrm{R}^{2}$ adjusted ), the Akaike Information Criterion (AIC), and the Model Selection Criterion (MSC). AIC is a criterion used in model selection. A low AIC indicates that the model is better. MSC developed by MicroMath Corporation is another criterion used in model selection. The MSC value greater than 2 or 3 gives an idea of the suitability of the model [24,25]. Considering these criteria, the best fit was found for Korsmeyer-Peppas model. Korsmeyer-Peppas fitting graph was shown in Figure 5. The parameter of this model is $\mathrm{n}$ exponent and $\mathrm{n}$ values smaller than 0.45 means that the release is diffusion controlled [26]. The $\mathrm{n}$ value for F5 nanoparticles was 0.4015 .

Table 4. Applied mathematical models to the release data of SAMe loaded chitosan nanoparticles and their statistical evaluation by DDSolver program.

\begin{tabular}{llccccc}
\hline Model & Equation & $\mathrm{R}^{2}$ & $\mathrm{R}^{2}$ adjusted & AIC & MSC & $\mathrm{n}$ \\
\hline Zero-order model & $F=k_{0} * t$ & 0.2781 & 0.2781 & 111.210 & -0.114 & - \\
First-order model & $F=100^{*}\left(1-e^{\left.-k 1^{*} t\right)}\right.$ & 0.9517 & 0.9517 & 78.749 & 2.591 & - \\
& & & & & & - \\
Hixson-Crowell & $F=100^{*}\left[1-\left(1-k_{\mathrm{HC}}{ }^{*} t\right)^{3}\right]$ & 0.9138 & 0.9138 & 85.708 & 2.011 & - \\
Higuchi & $F=k_{\mathrm{H}^{*}} t^{*} 5$ & 0.8669 & 0.8669 & 80.184 & 1.835 & - \\
Hopfenberg & $F=100^{*}\left[1-\left(1-k_{\mathrm{HB}}{ }^{*} t\right)^{n]}\right.$ & 0.9155 & 0.9070 & 87.468 & 1.864 & 3.000 \\
Korsmeyer-Peppas & $F=k_{\mathrm{KP}^{*}} t^{n}$ & 0.9924 & 0.9909 & 24.128 & 3.802 & 0.4015 \\
\hline
\end{tabular}

*In all models, $\boldsymbol{F}$ is the fraction (\%) of drug released in time $\mathbf{t}, \boldsymbol{k} \mathbf{0}$ : zero-order release constant, $\boldsymbol{k} \mathbf{1}$ :first-order release constant, $\boldsymbol{k H C}$ : Hixson-Crowell release constant $\boldsymbol{k} \mathbf{H}$ : Higuchi release constant, $k \mathrm{HB}$ : Hopfenberg release constant, $\boldsymbol{k K P}$ : release constant incorporating structural and geometric characteristics of the drug-dosage form, $n$ : is the diffusional exponent indicating the drug-release mechanism.

Similarity factor, $\mathrm{f}_{2}$ was calculated to compare the dissolution profiles obtained for pure SAMe and chitosan nanoparticles. Values of $f_{2}$ higher than $50(50-100)$ indicate the similarity or equivalence of the two profile [27]. The calculated $\mathrm{f}_{2}$ value was 40.11 denoting that the profiles were different and chitosan has extended the release of SAMe compared to pure SAMe.

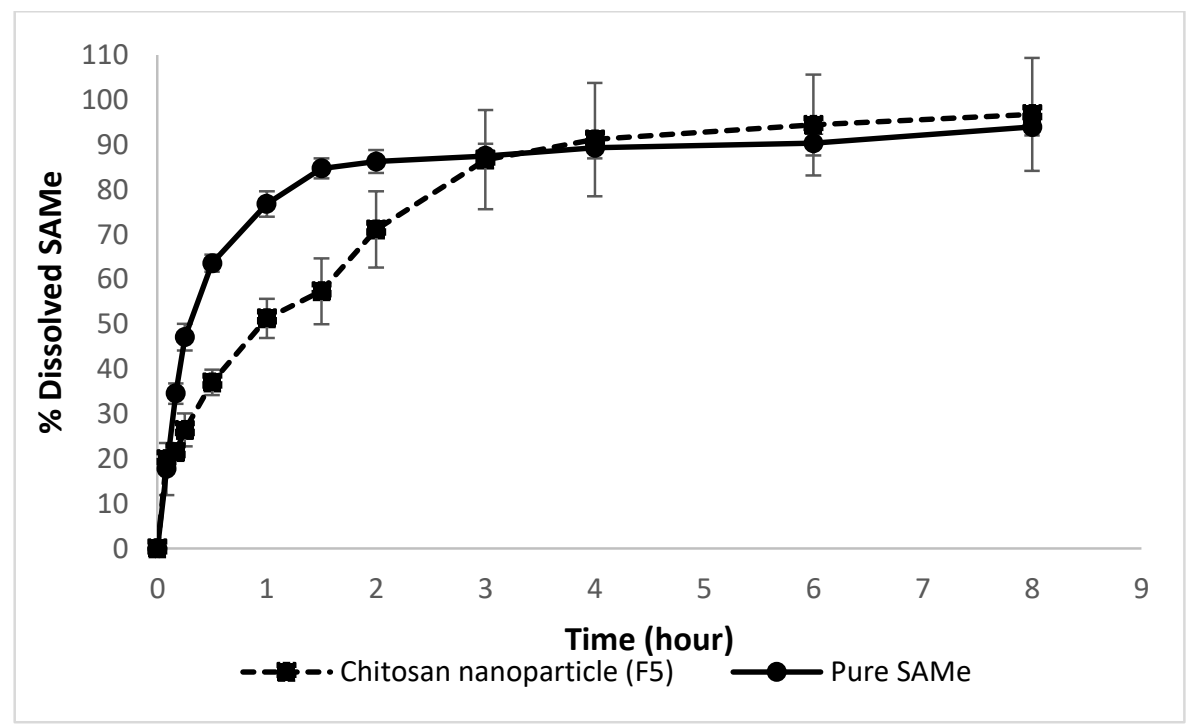

Figure 4. Drug release profiles. 


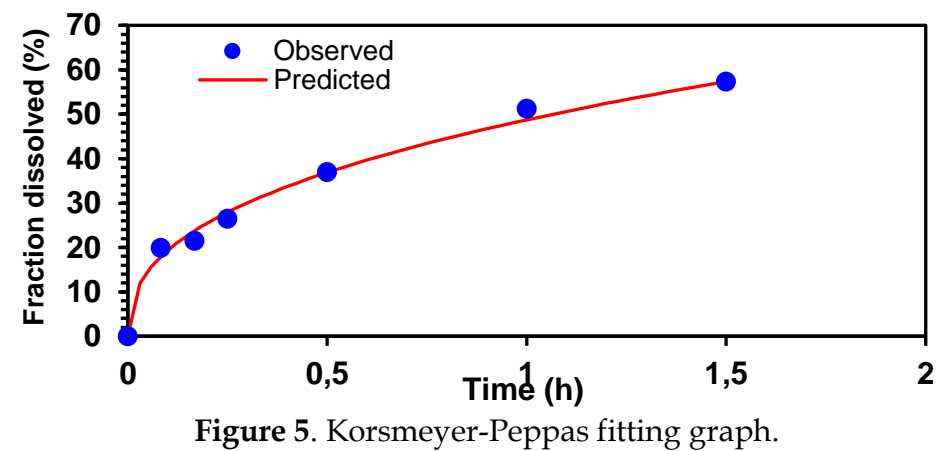

\subsection{Investigations on drug-excipient interaction in chitosan nanoparticles}

\subsubsection{FTIR studies}

FTIR studies were carried out to characterize the chemical structure of chitosan nanoparticles prepared by ionic gelation of chitosan with TPP solutions. FTIR spectra of SAMe, chitosan, TPP and SAMe loaded chitosan nanoparticles were shown in Figure 6. In Figure 6b, the characteristic peak at $3259 \mathrm{~cm}^{-1}$ is the combined peaks of the stretch bands bound to the $\mathrm{NH}_{2}$ and $\mathrm{OH}$ groups in the chitosan polymer. The peak at $1617 \mathrm{~cm}^{-1}$ is thought to belong to the $\mathrm{CONH}_{2}$ group (amide carbonyl stretch band), and the peak at $1507 \mathrm{~cm}^{-}$ ${ }^{1}$ (N-H bending band) shows a high degree of deacetylation of the chitosan. The decrease in the sharpness of the peak at $3259 \mathrm{~cm}^{-1}$ in the chitosan nanoparticle indicates the formation of hydrogen bonds (Figure $6 \mathrm{~d}$ ). As seen in the IR spectra of chitosan and SAMe (Figure 6a and b) the peaks at $1507 \mathrm{~cm}^{-1}$ wherein the N-H bending band, shifted $1526 \mathrm{~cm}^{-1}$ wherein the nanoparticles spectra. This shows that the ammonium groups were crosslinked with TPP and ionic gelation was induced. In addition, the spectrum band at $889 \mathrm{~cm}^{-1}$ in the chitosan nanoparticle spectrum (Figure $6 \mathrm{~d}$ ) was related to the aromatic structure $=\mathrm{CH}$ bending band in SAMe molecule and $\mathrm{P}=\mathrm{O}$ stretch band at $1209 \mathrm{~cm}^{-1}$ was related to TPP molecules [28].

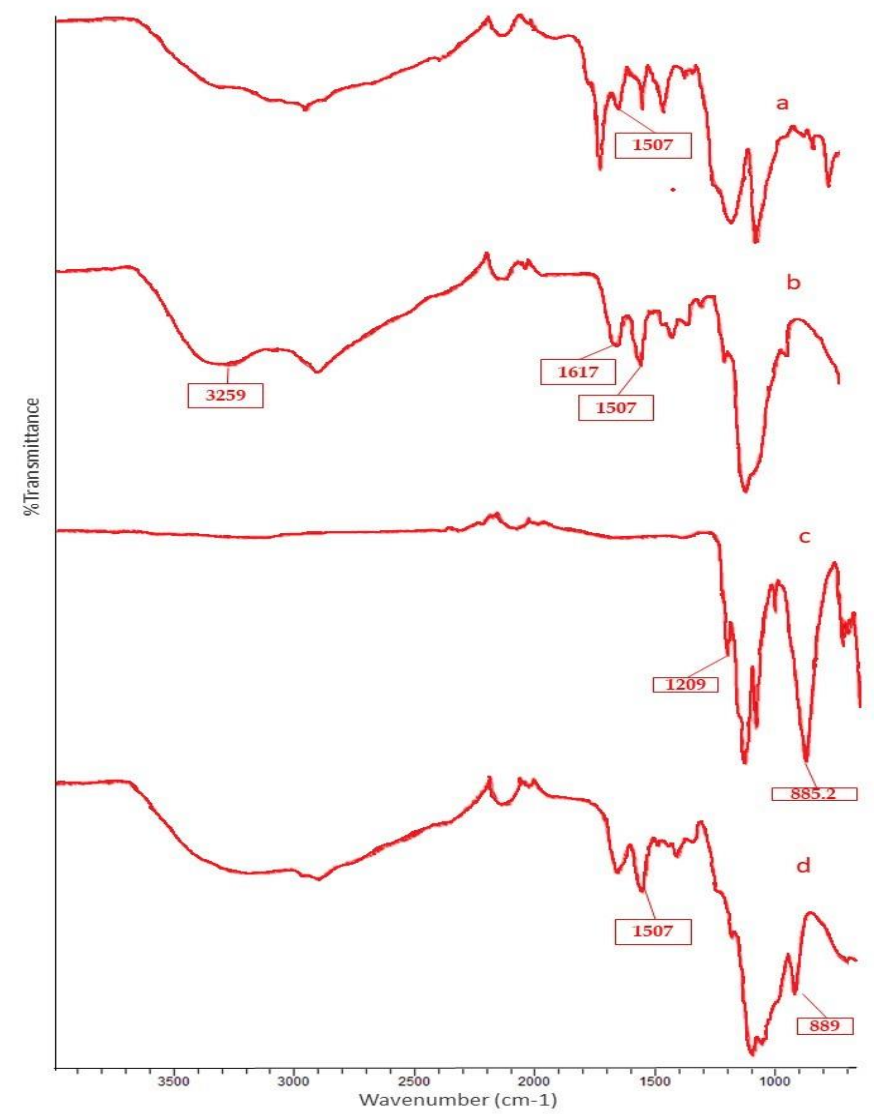

Figure 6. IR Spectra of (a) SAMe; (b) chitosan; (c) TPP; (d) F5. 


\subsubsection{DSC studies}

Thermograms of chitosan, SAMe, TPP and F5 formulation were given in Figure 7. In the chitosan thermogram, an initial thermal transition at $60-80^{\circ} \mathrm{C}$ and a sharp endothermic peak at $233.6^{\circ} \mathrm{C}$ were observed (Figure 7a). The glass transition temperature of dry chitosan was appeared at $118^{\circ} \mathrm{C}$. However, in the presence of water, this value was decreased to $61^{\circ} \mathrm{C}$, indicating the plasticizer role of water and formation of intermolecular hydrogen bonds with the amine and hydroxyl groups of the chitosan [29]. The sharp endothermic peak was thought to be the melting point [30].

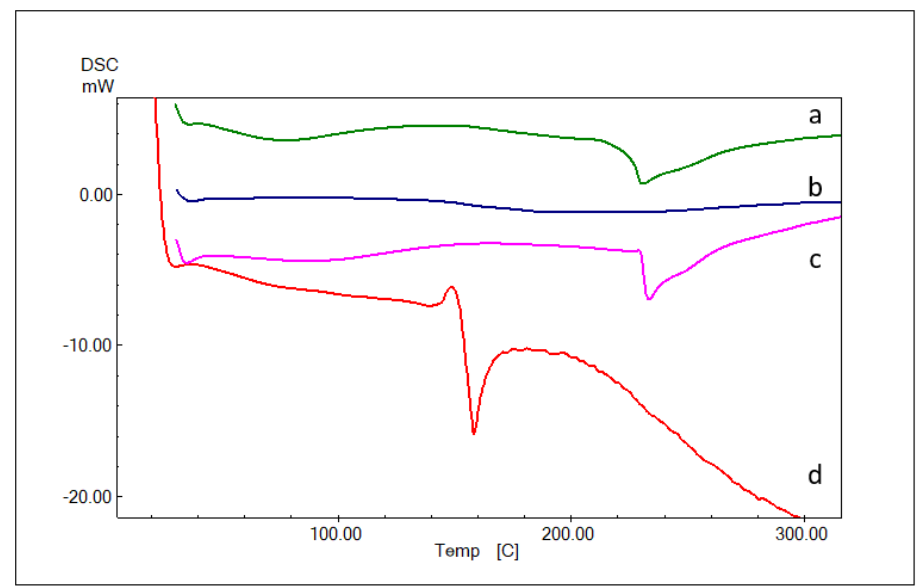

Figure 7. DSC thermograms (a: chitosan, b: TPP, c:F5, d:SAMe).

The thermogram of SAMe showed an endothermic peak at $158.4^{\circ} \mathrm{C}$ pointing out the melting of the SAMe and subsequent decomposition (Figure 7d). In Figure 7c, the characteristic peak of chitosan was observed, as the endothermic peak of SAMe disappeared completely. Thus, it can be concluded that SAMe is found in amorphous state in nanoparticles.

\section{CONCLUSION}

The aim of this study was to develop SAMe loaded chitosan nanoparticles. Chitosan nanoparticles were produced by ionic gelation characterized by dropwise addition of anionic TPP solution to the cationic chitosan solution.

A three - factor, two - level factorial design $\left(2^{3}\right)$ was formed and a nonlinear regression analysis was applied. Chitosan concentration and SAMe amount were significant parameters affecting the particle size of nanoparticles; TPP concentration was found to have significant effect on the process yield $(p<0.05)$. According to the results obtained, F5 formula which includes SAMe and chitosan at high levels and TPP at low level, was determined as the optimum formulation with the highest loading efficiency. Drug release study, FTIR and DSC analysis were performed on F5. According to the to Korsmeyer-peppas model, SAMe was released by a diffusion controlled mechanism from chitosan nanoparticles. FTIR and DSC results demonstrated the chemical interaction between chitosan and TPP, and the amorphous form of SAMe encapsulated in chitosan nanoparticles.

As a result, chitosan nanoparticles loaded with SAMe could be produced successfully. But, further studies need to be performed in order to improve encapsulation efficiency of SAMe and process yield of nanoparticles.

\section{MATERIALS AND METHODS}

\subsection{Materials}

Chitosan chloride (Protasan ${ }^{\circledR} \mathrm{Cl} 214$, viscosity 20-200 mPa.s, Mw 150-400 kDa, deacetylation degree $>90 \%$ ) was purchased from FMC Biopolymers (Norway). Sodium tripolyphosphate pentabasic (TPP) was purchased from Sigma-Aldrich Co. (St. Louis, Missouri) and S-adenosyl-1-methionine 1,4 butanedisulfonate were purchased from Carbosynth NA (England). Ultrapure water purified by Milli-Q Plus system (Millipore Corp., Molsheim, France) was used in all experiments. All other chemicals and reagents were of analytical grade. 


\subsection{Preparation of chitosan nanoparticles}

Chitosan nanoparticles were formed by ionotropic gelation between chitosan and TPP [31]. Briefly, chitosan and TPP were dissolved in bidistilled water at a concentration of 1-3 mg.mL-1 $(\mathrm{w} / \mathrm{v})$ and $0.5-1$ mg.mL $\mathrm{mL}^{-1}(\mathrm{w} / \mathrm{v})$, respectively. A $6 \mathrm{~mL}$ of TPP solution was added by instillation at a rate of $1.25 \mathrm{~mL} / \mathrm{min}$ to $15 \mathrm{~mL}$ of chitosan solution ( $\mathrm{pH} 4.7$ ) which was being mixed at $400 \mathrm{rpm}$ on a magnetic stirrer at room temperature to produce nanoparticles simultaneously. In order to obtain SAMe loaded chitosan nanoparticles, SAMe was dissolved in the chitosan solution. The compositions of the prepared formulations were given in Table 5 and 6.

Table 5. Variable level of $2^{3}$ factorial design for chitosan nanoparticles.

\begin{tabular}{ccc}
\hline Variable level & $\mathbf{- 1}$ (low) & +1 (high) \\
\hline Chitosan Concentration(mg.mL $\left.\mathrm{mL}^{-1}\right)\left(\mathrm{X}_{1}\right)$ & 1.0 & 3.0 \\
TPP Concentration(mg.mL & -1 \\
SAMe amount $(\mathrm{mg})\left(\mathrm{X}_{2}\right)$ & 0.5 & 1.0 \\
\hline
\end{tabular}

Resulting nanoparticles were ultracentrifuged at $10^{\circ} \mathrm{C}$ for 1 hour at $26000 \mathrm{rpm}$ to separate the unloaded drug. The precipitated SAMe loaded nanoparticles were suspended in $1.5 \mathrm{~mL}$ distilled water and freeze-dried in a lyophilizer at $-80^{\circ} \mathrm{C}$ and under pressure of 0.01 mbar (Chriss Gamma 2-16 LSCplus ,England).

Table 6. The composition of chitosan nanoparticle formulations.

\begin{tabular}{|c|c|c|c|c|c|c|c|c|c|c|}
\hline Contents & F1 & F2 & F3 & F4 & F5 & F6 & F7 & F8 & * & * \\
\hline $\begin{array}{c}\text { Chitosan } \\
\text { concentration } \\
\left(\mathrm{mg} \cdot \mathrm{mL}^{-1}\right)(15 \mathrm{~mL})\end{array}$ & 1.0 & 1.0 & 1.0 & 1.0 & 3.0 & 3.0 & 3.0 & 3.0 & 3.0 & 3.0 \\
\hline $\begin{array}{c}\text { TPP } \\
\text { Concentration } \\
\left(\mathrm{mg} \cdot \mathrm{mL}^{-1}\right)(6 \mathrm{~mL})\end{array}$ & 0.5 & 0.5 & 1.0 & 1.0 & 0.5 & 0.5 & 1.0 & 1.0 & 0.5 & 0.5 \\
\hline $\begin{array}{l}\text { SAMe amount } \\
(\mathrm{mg})\end{array}$ & 13.5 & 4.5 & 13.5 & 4.5 & 13.5 & 4.5 & 13.5 & 4.5 & 13.5 & 13.5 \\
\hline $\begin{array}{l}\text { Stirring rate } \\
\text { (RPM) }\end{array}$ & 400 & 400 & 400 & 400 & 400 & 400 & 400 & 400 & 400 & 400 \\
\hline
\end{tabular}

\subsection{Development and validation of quantification method}

UV spectrophotometry was used for the assay of SAMe in the chitosan nanoparticles. After determining the maximum absorbance wavelength $\left(\lambda_{\max }\right)$ of SAMe in water, simulated gastric fluid $(\mathrm{pH} 1.2)$ (SGF) and simulated colonic fluid ( $\mathrm{pH} 5.8$ ) ( SCoF2 ), serial concentrations $(2.5-50 \mu \mathrm{g} / \mathrm{mL}$ ) were prepared by diluting from $50 \mu \mathrm{g} / \mathrm{mL}$ stock solution [32]. Absorbances of these solutions were read at the maximum absorbance wavelength $(260 \mathrm{~nm})$ (Agilent Carry $60 \mathrm{UV}-\mathrm{Vis}$, Santa Clara, USA ). Calibration curve was constructed by plotting known concentrations of SAMe on the $x$ axis and correspondingly absorbance values on $\mathrm{Y}$ axis. A calibration equation was calculated by a statistical programme (SPSS 20.0 biostatistics software). The developed assay method was validated and the analytical validation parameters (precision, limit of detection, limit of quantification, stability) were determined.

\subsection{Process yield}

Process yield of the nanoparticles were calculated gravimetrically. Nanoparticle dispersions were ultracentrifuged $\left(26000 \mathrm{rpm}, 1\right.$ hour, $\left.10^{\circ} \mathrm{C}\right)$ and the precipitates were freeze-dried in the lyophilizator (Chriss Gamma 2-16 LSCplus, England) for 24 hour. The process yield was calculated through Equation 1.

$$
\text { P.Y. }(\%)=\frac{\text { Nanoparticles weight }}{\text { Total solids weight }(\text { Chitosan }+ \text { TPP }+ \text { SAMe })} \times 100
$$




\subsection{Characterization of nanoparticles}

\subsubsection{Particle size analysis}

Particle size, size distribution and polydispersity index of chitosan nanoparticles were determined by dynamic light scattering (DLS) method using zetasizer (NanoSeries, Nano-ZS, Malvern Instruments, UK). Analyses were performed at $25^{\circ} \mathrm{C}$ with He-Ne laser $(633 \mathrm{~nm})$ with a scattering angle of $173^{\circ}$. Disposable zetasizer cuvettes were used for the measurement of nanoparticle suspensions and 6 measurements were made for each sample.

\subsubsection{Zeta potential}

Zeta potential of nanoparticles was measured to determine the surface charge of the nanoparticles on the zetasizer (NanoSeries, Nano-ZS, Malvern Instruments, UK) $(n=4)$. For zeta potential measurement, disposable folded capillary cuvette was used.

\subsubsection{Encapsulation efficiency}

Indirect method was used for the quantification of encapsulation efficiency of SAMe in chitosan nanoparticles. After ultracentrifugation of the nanoparticles, the amount of unloaded SAMe in the supernatant was determined by UV spectrophotometer using the calibration equation for SAMe in water $(n=3)$. The entrapment efficiency (EE \%) was calculated through Equation 2.

$$
\text { E. E. }(\%)=\frac{\text { Total SAMe weight }- \text { Unloaded SAMe weight }}{\text { Total SAMe weight }} \times 100
$$

\subsubsection{Release studies}

SAMe release from the nanoparticles was examined for $8 \mathrm{~h}$ using dissolution tester equipped with mini paddles and mini vessels (Agilent 708DS CA, USA). Dialysis membranes (molecular weight cut off 12000 Da, SpectrumLabs, CA, USA) were hydrated with water by overnight incubation before the release experiments. Pure SAMe solution containing $2 \mathrm{mg}$ SAMe or chitosan nanoparticles containing $2 \mathrm{mg}$ SAMe dispersed in 1.0 $\mathrm{mL}$ of ultra -pure water was placed into the dialysis membrane and the closed dialysis bags were sunk in release medium. Release study was carried out in $100 \mathrm{~mL}$ of SGF medium $\left(37 \pm 0.5^{\circ} \mathrm{C}\right)$ for 2 hours, then dialysis bags were transferred to $100 \mathrm{~mL}-\mathrm{SCoF} 2$ medium $\left(37 \pm 0,5^{\circ} \mathrm{C}\right)$. The paddles were rotated at $75 \mathrm{rpm}$ and samples (3 mL) were withdrawn at 5., 10., 15., 30., 60., 90., 120., 180., 240., 360., 480. min. Fresh medium was added to maintain a constant total volume and samples were analyzed spectrophotometrically.

In order to evaluate the similarity between the release profiles of the pure SAMe (R) and SAMe in the nanoparticles $(\mathrm{T}), \mathrm{f}_{2}$ similarity factor was calculated (Equation 3 ) [28].

$$
\mathrm{f}_{2}=50 \log \left\{\left[1+\frac{1}{\mathrm{n}} \sum_{\mathrm{i}=1}^{\mathrm{n}}(\mathrm{Rt}-\mathrm{Tt})^{2}\right]^{-0.5} \times 100\right\}
$$

$\mathrm{R}_{\mathrm{t}}$ : Percent dissolved SAMe at time $\mathrm{t}$

$\mathrm{T}_{\mathrm{t}}$ : Percent released SAMe from chitosan nanoparticles at time $\mathrm{t}$

$\mathrm{n}$ : Number of samples taken in release medium

The mathematical models (zero-order, first-order, Hixson-Crowell, Higuchi, Korsmeyer-Peppas and Weibull), shown in Table 4 were fitted to the data obtained from release test of nanoparticles with the nonlinear regression module of Microsoft Excel, DDSolver add-in. Determination coefficients $\left(R_{2}\right), R_{2}$ adjusted, MSC, and AIC values for each model were estimated.

\subsection{FTIR spectroscopic analysis}

Fourier transform infrared (FTIR) spectra of SAMe, chitosan, TPP and SAMe loaded nanoparticles were taken by an FTIR spectrophotometer (Agilent Cary 630 FTIR spectrometer, USA). The sample powders were scanned with the crystal tip of the instrument to obtain spectra at wavenumbers ranging $4000 \mathrm{~cm}^{-1}$ to 650 $\mathrm{cm}^{-1}$. 


\subsection{DSC studies}

Thermal analyses of SAMe loaded nanoparticles, chitosan, TPP and SAMe were performed by differential scanning calorimetry (DSC) (TA Instruments Q100, NewCastle, DE, USA). Thermograms of powders were taken at a scanning rate $20^{\circ} \mathrm{C} / \mathrm{min}$ over a temperature range $20-300^{\circ} \mathrm{C}$ under nitrogen. The reference substance was indium.

\subsection{Factorial design}

Chitosan concentration $\left(X_{1}\right)$, TPP concentration $\left(X_{2}\right)$ and SAMe amount $\left(X_{3}\right)$ in the formulations of nanoparticles were used as independent factors. The measured characteristics of the nanoparticles were the dependent factors, that is, particle size $\left(n m, Y_{1}\right)$, zeta potential $\left(m V, Y_{2}\right)$, encapsulation efficiency $\left(\%, Y_{3}\right)$ and process yield $\left(\%, Y_{4}\right)$. Three factor, two level full factorial design $\left(2^{3}\right)$ was created to investigate the effect of independent variables $\left(\mathrm{X}_{\mathrm{i}}\right)$ on dependent variables $\left(\mathrm{Y}_{\mathrm{i}}\right)$. The levels and independent factors' values are given in Table 5. Contents of the formulations were given in the Table 6. A polynomial equation was used to quantify the effects of independent factors on the measured responses (Equation 4).

$$
Y=B_{0}+B_{1} X_{1}+B_{2} X_{2}+B_{3} X_{3}+B_{12} X_{1} X_{2}+B_{13} X_{1} X_{3}+B_{23} X_{2} X_{3}+B_{123} X_{1} X_{2} X_{3}
$$

Y : Measured characteristics of nanoparticles

$\mathrm{B}_{0} \quad$ : Intercept

$\mathrm{B}_{\mathrm{i}} \quad$ : Coefficients

$\mathrm{X}_{\mathrm{i}} \quad$ : Level of the independent factors

Standard error of B coefficients and descriptive statistics of regression models were calculated with Statistica 7.0 for Windows (Statsoft, Tulsa, OK, USA), with 2 ** (Kp, standard design) analysis module [33,34] .

Acknowledgements: This study was supported by the Turkish Scientific and Technological Research Council (TÜBİTAK) under grant 115S339.

Author contributions: Concept - N.Y.; A.D.E.; Z.S.B.; Design - A.D.E.; Z.S.B.; N.Y.; Supervision - N.Y.; Resources - N.Y. A.D.E.; Z.S.B. Materials - N.Y.; Data Collection and/or Processing - A.D.E.; Z.S.B.; N.Y.; Analysis and/or Interpretation - A.D.E.; Z.S.B.; N.Y.; Literature Search - A.D.E.; Z.S.B.; N.Y.; Writing - A.D.E.; Critical Reviews - A.D.E.; Z.S.B.; N.Y.

Conflict of interest statement: The authors declared no conflict of interest.

\section{REFERENCES}

[1] Birrenbach G, Speiser PP. Polymerized micelles and their use as adjuvants in immunology. J Pharm Sci. 1976; 65: 1763-1766. [CrossRef]

[2] des Rieux A, Fievez V, Garinot M, Schneider YJ, Preat V. Nanoparticles as potential oral delivery systems of proteins and vaccines: a mechanistic approach. J Control Release. 2006; 116(1): 1-27. [CrossRef]

[3] Hoshyar N, Gray S, Han H, Bao G. The effect of nanoparticle size on in vivo pharmacokinetics and cellular interaction. Nanomed. 2016. [CrossRef]

[4] Zhao Y, Wang Y, Ran F, Cui Y, Liu C, Zhao Q, et al. A comparison between sphere and rod nanoparticles regarding their in vivo biological behavior and pharmacokinetics. Sci Rep. 2017; 7(1): 1-11. [CrossRef]

[5] Lamprecht A, Schäfer U, Lehr CM. Size-Dependent Bioadhesion of Micro- and Nanoparticulate Carriers to the Inflamed Colonic Mucosa. Pharm Res. 2001; 18(6): 788-793. [CrossRef]

[6] Pan Y, Li Y, Zhao H, Zheng J, Xu H, Wei G, et al. Bioadhesive polysaccharide in protein delivery system: chitosan nanoparticles improve the intestinal absorption of insulin in vivo. Int J Pharm. 2002; 249(139): 139-147. [CrossRef]

[7] Patel D, Naik S, Misra A. Improved transnasal transport and brain uptake of tizanidine HCl-loaded thiolated chitosan nanoparticles for alleviation of pain. J Pharm Sci. 2012; 101(2): 690-706. [CrossRef]

[8] Li Z, Jiang H, Xu C, Gu L. A review: Using nanoparticles to enhance absorption and bioavailability of phenolic phytochemicals. Food Hydrocoll. 2015; 43: 153-164. [CrossRef]

[9] Iglesias N, Galbis E, Díaz-Blanco MJ, Lucas R, Benito E, de-Paz MV. Nanostructured chitosan-based biomaterials for sustained and colon-specific resveratrol release. Int J Mol Sci. 2019; 20, 398. [CrossRef] 
[10] Rampino A, Borgogna M, Blasi P, Bellich B, Cesaro A. Chitosan nanoparticles: preparation, size evolution and stability. Int J Pharm. 2013; 455(1-2): 219-228. [CrossRef]

[11] Barbari GR, Dorkoosh FA, Amini M, Sharifzadeh M, Atyabi F, Balalaie S, et al. A novel nanoemulsion-based method to produce ultrasmall, water-dispersible nanoparticles from chitosan, surface modified with cell-penetrating peptide for oral delivery of proteins and peptides. Int J Nanomed. 2017; 12: 3471-3483. [CrossRef]

[12] Prego C, Torres D, Alonso MJ. The potential of chitosan for the oral administration of peptides. Expert Opin Drug Deliv. 2005; 2(5): 843-854. [CrossRef]

[13] Bottiglieri T. S-Adenosyl-L-methionine (SAMe): from the bench to the bedside-molecular basis of a pleiotrophic molecule. Am J Clin Nutr. 2002; 76: 1151-1157. [CrossRef]

[14] Lieber CS, Packer L. S-Adenosylmethionine: molecular, biological, and clinical aspects - an introduction. Am J Clin Nutr. 2002; 76: 1148-1150. [CrossRef]

[15] The Norwegian Scientific Committee for Food and Environmen, Risk assessment of histidine, methionine, Sadenosylmethionine and tryptophan, 2013.

[16] https://vkm.no/download/18.175083d415c86c573b59c3a7/1501675375589/ba7a85274a.pdf (accessed July 25, 2019).

[17] Magesh B, Naidu PY, Rajarajeswari GR. S-adenosyl-l-methionine (SAMe)-loaded nanochitosan particles: synthesis, characterisation and in vitro drug release studies. J Exp Nanosci. 2015; 10(11): 828-843. [CrossRef]

[18] Food And Drug Administration, Reviewer guidance validation of chromatographic methods, November/1994.

[19] https://www.fda.gov/media/75643/download (accessed July 25, 2019).

[20] Ozkan Y, Tas C, Ozkan CK, Bayrak Z, Esim O, Ozkan S. İlaçların analiz ve kalite kontrollerinde kullanılan analitik yöntemlerin geçerliliği (validasyon), Gülhane Askeri Tıp Akademisi, Ankara, Türkiye, 2011.

[21] Food And Drug Administration, Appendix 1 - ORA validation and verification guidance for human drug analytical methods.

[22] https://www.fda.gov/media/82998/download (accessed July 25,2019).

[23] Shu XZ, Zhu KJ. The influence of multivalent phosphate structure on the properties of ionically cross-linked chitosan films for controlled drug release. Eur J Pharm Biopharm. 2002; 54: 235-243. [CrossRef]

[24] Fan W, Yan W, Xu Z, Ni H. Formation mechanism of monodisperse, low molecular weight chitosan nanoparticles by ionic gelation technique. Colloids Surf B Biointerfaces. 2012; 90: 21-27. [CrossRef]

[25] Janes KA, Fresneau MP, Marazuela A, Fabra A, Alonso MJ. Chitosan nanoparticles as delivery systems for doxorubicin. J Control Release. 2001; 73: 255-267. [CrossRef]

[26] Omar Zaki SS, Ibrahim MN, Katas H. Particle size affects concentration-dependent cytotoxicity of chitosan nanoparticles towards mouse hematopoietic stem cells. J Nanotechnoly. 2015; 2015: 1-5. [CrossRef]

[27] Zhang Y, Huo M, Zhou J, Zou A, Li W, Yao C, et al. DDSolver: an add-In program for modeling and comparison of drug dissolution profiles. AAPS J. 2010; 12(3): 263-271. [CrossRef]

[28] Öztürk AA, Güven UA. Cefaclor monohydrate loaded microemulsion formulation for topical application: Characterization with new developed UPLC method and stability study. J Res Pharm. 2019; 23(3): 426-440. [CrossRef]

[29] Siepmann J, Peppas NA. Modeling of drug release from delivery systems based on hydroxypropyl methylcellulose (HPMC). Adv Drug Deliv Rev. 2001; 48: 139-157. [CrossRef]

[30] Moore JW, Flanner HH. Mathematical comparison of curves with an emphasis on in vitro dissolution profiles. Pharm Technol. 1996; 20: 64-74.

[31] Qi L, Xu Z, Jiang X, Hu C, Zou X. Preparation and antibacterial activity of chitosan nanoparticles. Carbohydr Res. 2004; 339(16): 2693-2700. [CrossRef]

[32] Dhawade PP, Jagtap RN. Characterization of the glass transition temperature of chitosan and its oligomers by temperature modulated differential scanning calorimetry. Adv Appl Sci Res. 2012; 3(3): 1372-1382.

[33] Neufeld L, Bianco-Peled H. Pectin-chitosan physical hydrogels as potential drug delivery vehicles. Int J Biol Macromol. 2017; 101: 852-861. [CrossRef]

[34] Calvo P, Remunan lopez C, Vila-Jato JL, Alonso MJ. Novel hydrophilic chitosan-polyethylene oxide nanoparticles as protein carriers. J Appl Polym Sci. 1997; 63(1): 125-132. [CrossRef] 
[35] Bou-Chacra N, Curo Melo KJ, Morales IAC, Stippler ES, Kesisoglou F, Yazdanian M, et al. Evolution of choice of solubility and dissolution media after two decades of biopharmaceutical classification system. AAPS J. 2017; 19(4): 989-1001. [CrossRef]

[36] Yüksel N, Beba L. Preparation and optimization of superabsorbent hydrogel micromatrices based on poly(acrylic acid), partly sodium salt-g-poly(ethylene oxide) for modified release of indomethacin Drug Dev Ind Pharm. 2009; 35(6): 756-767. [CrossRef]

[37] Surya Teja SP, Damodharan N. 23 full factorial model for particle size optimization of methotrexate loaded chitosan nanocarriers: a design of experiments (DoE) approach. Biomed Res Int. 2018; Article ID 7834159. [CrossRef]

This is an open access article which is publicly available on our journal's website under Institutional Repository at http://dspace.marmara.edu.tr. 